\title{
The Human Resource Management in Call Centres: The Development of a Questionnair
}

\section{La Dirección de Recursos Humanos en los Call Centres: Desarrollo de un Cuestionario}

\author{
Filipa Catanheira and María José Chambel \\ University of Lisbon
}

\begin{abstract}
This article reports on the development of a questionnaire of HR practices in call centres. Data were collected in 11 call centres operated by 8 organizations in Portugal. Construct validity was examined with a confirmatory factor analysis $(n=811)$, which confirmed the 6 factor structure: Electronic and traditional monitoring intensity, traditional monitoring content, training, participation and performance-related pay scales. Cronbach's alpha revealed sufficient internal consistency of scales' scores, except for training and performance-related pay. Eight HR managers were interviewed for the inspection of the content and criterion-related validities of the scales. Qualitative data showed that HR practices were present and relevant to call centres, but also that there were significant differences that allowed call centres' characterization in terms of presence/intensity of each HR practice. Analysis of variance demonstrates scales' convergent validity as, in general, employees' perceptions of HR practices vary across call centres in the predicted ways.

Keywords: Call centres, HR practices, qualitative and quantitative methodology.
\end{abstract}

\begin{abstract}
Resumen. En este artículo se informa sobre el desarrollo de un cuestionario para evaluar las prácticas de recursos humanos en los Call Centres. Los datos fueron recogidos en 11 centros gestionados por ocho organizaciones en Portugal. La validez de constructo examinada con un análisis factorial confirmatorio $(\mathrm{n}=811)$, la cual confirma una estructura factorial en seis dimensiones: la intensidad de la vigilancia tanto electrónica como tradicional, la supervisión, la formación, la participación y la valoración del rendimiento asociado a las escalas salariales. La consistencia interna de los factores fue evaluada a través de un Alpha de Cronbach resultando satisfactoria, excepto para el factor de la formación y el factor sobre la remuneración ligada al desempeño que tuvieron una fiabilidad más baja. Ocho directivos de recursos humanos fueron entrevistados para analizar la validez de contenido y de criterio de los factores propuestos. Los datos cualitativos recogidos muestran que las prácticas de recursos humanos analizadas están presentes y son relevantes para los call centres, pero además se constató que existen diferencias significativas entre los centros analizados que permiten categorizarlos en términos de presencia/intensidad de cada una de las prácticas de recursos humanos utilizadas. A través de diversos análisis de varianza se demostró la validez convergente de la escala ya que, en general, la valoración de los trabajadores encuestados sobre la percepción de las prácticas de recursos humanos variaba entre los call centres en el sentido esperado en las hipótesis.

Palabras clave: Call centres, prácticas de recursos humanos, metodología cualitativa y cuantitativa.
\end{abstract}

Call centres are a growing part of the service industry all over the world and many call centres agent jobs have been created in this sector in the last decades (DBK, 2007). Portugal is no exception, with call centres growing at a rate of $20 \%$ per year (DBK, 2007) between 2003 and 2006. Call centres are complex organizations that have been characterized by the highly constrained nature of work, with employees working in isolation and the work being automatically allocated and tightly monitored (Taylor \& Bain, 1999;

Correspondence concerning this article should be addressed to Filipa Castanheira (fcastanheira@fp.ul.pt) \& Maria José Chambel (mjchambel@fp.ul.pt), Faculdade de Psicologia, Alameda da Universidade, 1649-013 Lisboa, Portugal. Filipa Castanheira's contribution to this paper was supported by a grant from the Fund for Science and Technology (FCT Grant number: SFRHBD/30488/2006).
Holman, 2005; Sprigg \& Jackson, 2006; Russel, 2008). Despite its first impression of work simplification and processes' standardization, call centres have developed complex Human Resource (HR) practices that are designed and chosen to ensure workers' behaviours and attitudes contribute to the improvement of organizational effectiveness and hence better performances (Batt, 2002; Batt \& Colvin, 2011; Combs, Liu, Hall, \& Ketchen, 2006; Lepak, Liao, Chung \& Harden, 2006; Wood, Holman, \& Stride, 2006). Research has demonstrated that, in call centres, one can find HR practices that give priority to quantitative criteria of calls and aim at reducing costs per customer transaction and HR practices that are implemented to improve service customization, encouraging their employees to be flexible and quality-oriented (Chambel \& 
Castanheira, 2010; Kinnie, Hutchinson, \& Purcell, 2000; Holman, 2005; Holman, Frenkel, Sorensen, \& Wood, 2009). The first have been labelled HR control practices, whereas the latter have been referred to as HR involvement practices (Lepak et al., 2006). Investigation has gathered empirical evidence which demonstrates that call centres combine HR control and $\mathrm{HR}$ involvement practices in an attempt to conciliate both quantitative and qualitative demands of service (Frenkel, Tam, Korczynski \& Shire, 1998; Kinnie et al., 2000). However, the majority of studies on HR practices in call centres rely on qualitative data or in checklists that are used to determine their presence or absence (Holman, 2005; Holman \& Wood, 2002). Moreover, as one of the central issues in studying call centres is determining how work organization and HR practices affect employees' attitudes, behaviours, stress and well being (Batt \& Colvin, 2011; Holman, 2005), it is important to develop an instrument that allows HR practices characterization in a more systematically way. In addition, it is also important to capture employees' perceptions of call centres' HR management as several authors have demonstrated that there might be a discrepancy in the way HR practices are designed and which organizational goals they are expected to achieve and the way they are implemented and experienced by employees (Guest, 2001; Nishii, Lepak, \& Schneider, 2008; Bashshur, Hernández, \& González-Roma, 2011). The present study intends to develop an instrument that accurately captures workers perceptions of HR practices in call centres' daily management. For that purpose, a written questionnaire was developed and answered by call centres' workers. Factorial structure and psychometric characteristics of the questionnaire scales were analysed. A confirmatory factorial analysis was performed and its results confirmed the existence of six HR scales, demonstrating questionnaires' construct validity. Based on HR managers' interviews data analyses and analysing the descriptive statistics of HR practices reported by employees, content and criterion-related validity of the scales was analysed. By confirming that each HR practice being evaluated in the questionnaire was pertinent and relevant for HR management in call centres, we ensured content validity. In addition, as we demonstrated that employees' perceptions of HR practices vary in accordance to HR managers' descriptions of HR practices, the present study demonstrated the convergent validity of the questionnaire scales.

\section{HR practices in call centres}

HR practices vary considerably across call centres depending on the relative importance that is given to the quantitative and the qualitative criteria of calls (Taylor, Hyman, Mulvey \& Bain, 2002; Holman, 2005; Holman et al., 2009). These two important calls' criteria have been used to explain HR management variation in call centres (Taylor et al., 2002) but, as mentioned by Kinnie et al., (2000) most call centres present a mixture of $\mathrm{HR}$ practices designed to maximize employee involvement and to control employee behaviour.

\section{HR control practices}

When call centres' priority is the quantity of calls (Taylor et al., 2002), in order to maximise volume, call centres deliver standardized services through short, standardized interactions with the clients, which, in turn, lead to the simplification of work process. Jobs tend to be narrow and well defined, with low skill requirements, low autonomy and very well defined procedures. To assure employee compliance with the specified rules and procedures, management tends to implement HR control practices (Lepak et al., 2006; Holman, 2005). Among the most common HR control practices in call centres, performance monitoring have been studied as HR practices designed to detect misconducts and ensure employee compliance to desired behaviours (Ball, 2010, Frenkel et al., 1998; Kinnie et al., 2000). There are two types of performance monitoring: the electronic and the traditional performance monitoring. Electronic performance monitoring involves the continuous computerized collection and analysis of quantitative indicators of calls, such as number of calls, call length, call volumes, sales; and the traditional form involves observation, listening to calls and work sampling (Holman, 2005). Traditional monitoring is usually performed to assess quality of interaction, such as accuracy of information, helpfulness, script adherence, sympathy and professional tone (Holman, 2005). Despite taking into consideration quality indicators of customer interaction, what characterizes traditional performance monitoring as a HR control practice is that it is designed to check on adherence to required procedures and scripted dialogues. These scripted dialogues can take the form of greeting messages or be more complex, defining alternative dialogues that guide the whole interaction with the customer as alternative arguments are presented depending on the customers' questions (Deery, Iverson, \& Walsh, 2002). Call centres differ in the uses of performance data collected through performance monitoring practices. For example, it can be deployed punitively to inform disciplinary proceedings or can be used to identify training needs and sustain employees' skills development programs, taking the form of constructive performance feedback (Holman, 2005; Frenkel et al., 1998). Monitoring practices can be measured either in terms of performance-related content (i.e., immediacy of feedback, clarity of performance criteria), or in terms of its beneficial purpose (i.e., developmental or punitive aims) or, finally, in terms of 
perceived intensity (Holman, Chissick \& Totterdell, 2002). Some authors argue that it is the perceived intensity of performance monitoring practices, i.e., the perception of increased surveillance means that has the most detrimental impact on workers and that, when performance monitoring practices are conducted in a developmental manner and based on regular feedback it can have positive effects (Holman et al., 2002; Ball, 2010). Therefore, one can argue that when call centres implement performance monitoring practices, either traditional and/or electronic, and use them as surveillance practices to control for time length and script adherence, it might be associated with higher perception of intensity (Ball, 2010; Sprigg \& Jackson, 2006). Holman and Wood (2002) found that almost all call centres in UK monitored employees electronically, but they varied in the way they communicated the data collected to their employees: $60 \%$ used overhead screens to show information, and individuals were given feedback on a daily basis in $30 \%$ of call centres, on a weekly basis in $32 \%$ and on a monthly basis in $22 \%$. In what concerns traditional monitoring, two thirds record calls on a regular basis and the other third only records trainees' calls. In one third of call centres, supervisors listen to calls on a daily basis, while in another third it is done on a monthly basis and $20 \%$ does it sporadically. Dialogue scripting is regularly used in only $17 \%$ of call centres, and the majority reports "not using it" or "using it only a little". The majority of call centres give feedback and coaching to their employees either monthly $(42 \%)$ or every few weeks $(42 \%)$.

\section{HR involvement practices}

When Quality is an important criterion of calls, call centres tend to implement HR practices that empower and motivate employees to be more willing to provide good service. Costumer-employee relationships are more complex and considered the main driver for profit margins and sales revenue. Therefore it is important that workers know how to make the appropriate decisions, how to innovate and provide customised services, displaying discretionary behaviour and building relationships with the customers (Taylor et al., 2002; Kinnie et al., 2000). To achieve these aims, call centres tend to implement HR involvement practices (Batt, 2002; Batt \& Colvin, 2011; Holman et al., 2009; Kinnie et al., 2000; Lepak et al., 2006). Among the most common HR involvement practices in call centres, training, participation programs and performancerelated pay are some of the most cited in the literature (Holman, 2005; Holman \& Wood, 2002).

Participation programs. These programs represent important HR involvement practices for they increase workers' participation in decision making process and promote direct commitment to organizations' success (Cotton, 1993). Decentralization of decision making, the feedback of customers' evaluations and organizations' results, challenges for idea capturing, the creation of semi-autonomous teams (Batt, 1999) and offline problem solving groups (Batt \& Appelbaum, 1995) are common participation programs that allow knowledge sharing, continuous learning and better problem solving on how to handle customers and new technology (Batt, 1999). Holman and Wood (2002) found that, among 142 call centres in UK, 58\% stated that they did not have a structured method for idea capturing. About 25\% reported using a formal suggestion scheme, while $17 \%$ implemented quality circles/semiautonomous groups.

Training. Training programs are designed to equip workers with the skills and knowledge needed to assign their jobs and improve their performances. There are initial training programs, designed to develop the skills needed to start performing the tasks, and ongoing training, as an indicator of call centres' commitment on the employees' improvement. Holman and Wood (2002) found that the average length of initial training is 12 days, following an average of 15 days training in the first year. After the first year, employees receive an average of 7 days training per year.

Performance related pay. These HR practices serve as mechanisms to motivate and reward discretionary effort employees' display at work. As Schneider and Bowen (1983) point out, these kinds of practices highlight the contingent nature of rewards and allow best performances to be recognised, keeping workers motivated and aligned with the organizations' strategic goals.

In order to develop a questionnaire to measure employees' perceptions of HR practices in call centres, the present study was conducted in two stages using different methodologies. Stage 1 aimed at developing a written questionnaire designed to ask employees how they evaluated electronic and traditional monitoring intensity, traditional monitoring content, training and participation programs and, finally, performance related pay. Based on literature review and experts' opinion, a total of 24 items were developed to measure six HR practices. Call centres HR managers also read the questionnaire and searched for ambiguous or unfamiliar items, and also examined whether it covered the most important aspects of HR management in their call centre. Taken together, these procedures were implemented to increase content validity, ensuring items and scales relevance and representativeness (Kline, 1994; Messick, 1980). In order to gather construct validity evidence, a confirmatory factor analysis was performed. As referred by Russell (2002), when one aims at analysing, in a multidimensional questionnaire, how well a hypothesized factor structure fits the observed data, confirmatory factor analysis is recommended. Therefore, the dimensionality of the scales was evaluated and, further, their psychometric properties were assessed. To determine scale scores' internal consisten- 
cy, the alpha coefficient was computed. Finally, Stage 2 , was designed to examine criterion-related validity of the questionnaire scales. In this stage, call centres' HR managers were interviewed in order to understand which HR practices were implemented in each call centre and compare how different call centres could combine different HR practices. Therefore, the test and criterion data were collected at the same time but with different methods in order to examine if employees' perceptions of HR practices are coherently related to HR managers' characterization of the same construct (Messick, 1980). By determining whether employees' perceptions of HR practices vary in accordance to the call centres' categorization based on managers interviews, concurrent convergent validity is analysed.

\section{Method}

\section{Participants and Procedure}

The data were collected from employees and managers at 11 call centres operated by 8 organizations in Portugal. Call centres were distributed in several distinct areas of the market: Energy (call centre 1); Bank credit (2); Internet technical support (3); TV Channels (4); Telecommunications (5, 6, 8, 9); Bank (10) and Car Insurance $(7,11)$.

Quantitative data was collected from 811 workers employed in the 11 call centres. We aimed at understanding how employees' evaluated HR practices. Therefore, a questionnaire survey was conducted within the employees. Employees' data collection varied across call centres. In some call centres, questionnaires were answered in small groups, during work schedule while in others, a questionnaire was given to individual employees, accompanied by a covering letter explaining the research main goals and emphasizing that participation was voluntary and responses would be kept confidential. Data collection took place during 2007, and each call centre received a written report of the most important conclusions of the study. Responses rate ranged from $71 \%$ to $100 \%$. From the respondents, 509 were female $(63.1 \%)$ and the average age was 27.21 years $(\mathrm{SD}=6.09$ years), with the youngest workers being 16 years old and the oldest 68 years old. The average tenure is 36.64 months and most of them work in full time schedule $(64.9 \%)$. Labour contract is also varied and $14.2 \%$ are temporary workers from an outsourcing firm that belongs to the call centres' firm group, $1.4 \%$ are temporary workers from an outsourcing temporary work firm, $4.9 \%$ are free lancers. The majority $(79.5 \%)$ are directly hired by the call centre, being $37 \%$ permanent workers and $63 \%$ fixed-term workers. Qualitative information was collected by the help of semi-structured interviews with call centres' HR managers. The interviews aimed at understanding call centres' HR practices and analysing whether these descriptions matched employees' perceptions and allowed distinctions to be made among employees from different call centres. Managers were interviewed because, as Lepak et al. (2006) argue the ability to comment accurately on how HR practices are organized and employees are managed is higher when key informants are intimately involved in the management of the referent employees. Eight HR managers were interviewed as two organizations were responsible for more than one call centre (call centres 2, 3 and 5 belong to the same organization and call centres 4 and 6 belong to another organization). Despite belonging to the same organization, these call centres have very distinct core business and different HR systems. Interviews were conducted by one member of the research team. This researcher has received basic training, prior to the interviews, and also has had previous experience in conducting interviews in research in organizational behaviour. Interviews took place during 2007, and on average, lasted 2 hours. The researcher took notes during the interview process and, afterwards, wrote a complete resume of the interview. This document contained the most relevant qualitative information gathered during the interview. This document was sent to the interviewee for validation of the qualitative data.

\section{Measures}

Human resource practices questionnaire. Based upon the theory described in Strategic Human Resource Management and call centres' literature, a questionnaire was developed to assess HR practices in call centres. Nevertheless, in accordance to what was previously documented by Boselie, Dietz and Boon (2005), the overwhelming majority of studies relied only on measures of presence of HR practices (i.e., a dichotomous scale for whether it is actually in effect 'yes' or 'no'). We found rather fewer measures reflecting intensity, an exception being Holman et al. (2002) study that examined the relationship between wellbeing and three performance monitoring characteristics in a call centre study. Being aware of previous studies' limitations, we used prior HRM studies in call centres as the basis for adapting and developing an initial pool of 36 items that covered the most representative HR practices in call centres, including monitoring practices, $\mathrm{R} \& \mathrm{~S}$, training, participation, socialization and performance-related pay practices (Wood et al., 2006; Batt, 2002; Holman et al, 2002; Sprigg \& Jackson, 2006). The second phase consisted on the research team performing a content analysis and looking for redundancies in the questions being asked. The research team had previously established some categories (which represented the main HR practices) and then listed the items developed for each category. 
Based on HR interviews and on the analysis of items' content, some items were eliminated because they were redundant or because they lacked utility in this specific context. For example, based on HR managers' interviews we learned that socialization tactics were imbedded in initial training; therefore, operators would not be able to classify them as an isolated HR practice. The final version was then sent to the HR managers (as field-experts), who individually read the list of items and scrutinized it for item's ambiguity, unfamiliar terms and vague concepts (Podsakoff, MacKenzie, Lee, \& Podsakoff, 2003). For example, based on their opinions, the sample of items evaluating R\&S practices were eliminated from the questionnaire. According to HR managers, call center operators are not aware of R\&S procedures or global R\&S strategy therefore would not be a reliable source of information for this practice. The research team read the eight HR managers' evaluations of the item's list and kept a final pool of 24-items. These items were developed specifically for this study and were the result of a task force performed by the research team and experts' opinion. The twenty-four items evaluated electronic and traditional monitoring intensity, traditional monitoring content clarity, training, participation programs and performance related pay. The electronic monitoring intensity scale is composed by 4 items (e.g., "During my work, my performance is monitored by the duration of calls") and the traditional monitoring intensity scale is composed by 5 items (e.g., "During my work, my performance is monitored by my sympathy with the costumer"). The traditional monitoring content scale is composed by 5 items (e.g., "During my performance monitoring, the most important is being nice to the client"). To evaluate participation programs, 4 items were developed (e.g. "In this call centre, we have group meetings and discuss about problems"). Three items related to training were included in the questionnaire (e.g., "We all have the opportunity to assist to training sessions to better perform our tasks"), and finally, performance-related pay scale was composed of three items (e.g., "My income depends on the quality of my performance"). All items were scored in a 5point likert scale ranging from never (1) to frequently (5). High scores on these scales indicate higher intensity of traditional and electronic performance monitoring, higher content clarity of traditional monitoring indicators, more training, more participation and more performance-related pay.

Interview. We adopted a semi-structured interview methodology for it allowed us the construction of a script that worked as a standard for comparing interviews and, at the same time, allowed us some flexibility to capture what is specific in each call centre's reality (Breakwell, 2000). HR managers were asked about the main HR practices implemented in the call centre, specifically monitoring practices and involvement practices, such as training, participation and perform- ance related pay, and also how they were related to each other.

\section{Results}

\section{Construct validity}

Structural equation modelling (SEM) and in particular Confirmatory Factor Analysis (CFA) with the AMOS software package (Arbuckle, 2003) was used to test the factor structures of all scales included in the HRM questionnaire. In all analyses, the Maximum Likelihood Estimation Method and the covariance matrix were used (Russell, 2002). Two CFA analyses were performed: a six-factor model, which reflected the structure of the HRM questionnaire, and a singlefactor; used to examine and control for the influence of common method bias (i.e., the Harman's single factor test; Podsakoff et al., 2003). Following established recommendations (Hu \& Bentler, 1999), we combined five fit indices to determine how the models fitted our data: Chi-square test, the Standardized Root Mean Square (SRMR), the Bentler Comparative Fit Index (CFI), the Bollen's Incremental Fit Index (IFI), and the Root Mean Square Error of Approximation (RMSEA). Levels of 0.94 or higher for $I F I$ and $C F I$ and levels of 0.06 or lower for RMSEA combined with levels of 0.08 or lower for $S R M R$ will be considered as indicators that models fitted the data reasonably well. The two models were compared based on Chi-square difference tests. Obtaining a good fit for the measurement model is critical to establish construct and discriminant validity and to inspect risks associated with common method variance (Podsakoff et al., 2003). The measurement model including all 6 latent variables (electronic and traditional monitoring intensity, traditional monitoring content clarity, training, participation programs and performance related pay) and their respective observed variables, exhibited an adequate fit to the data $\left(\chi^{2}(236)=683.29, p<.001 ;\right.$ SRMR $=.05 ;$ IFI $=$ .94; $\mathrm{CFI}=.95$; RMSEA $=.05)$ and all standardized regressions coefficients in the measurement models were significant at the 0.001 level (Figure 1).

The one-factor model exhibited very poor fit to the data $\left(\chi^{2}(251)=3783.93, p<.001 ;\right.$ SRMR $=.12 ;$ IFI $=.59 ; \mathrm{CFI}=.59 ; \mathrm{RMSEA}=.13)$, significantly worse than the measurement model $\left(\Delta \chi^{2}(15)=3100.64, p<\right.$ $.001)$. The Harman's single factor test provided a good indication that a single factor did not account for the majority of variance in our data (Podsakoff et al., 2003).

We then calculated internal reliability (Cronbach's alpha) for electronic monitoring intensity (.84), traditional monitoring intensity (.93), traditional monitoring content clarity (.85), training (.67), participation programs (.75) and performance related pay (.63). Training and performance related pay scale scores pre- 
Figure 1. Confirmatory Factor Analysis (Six-factor model)

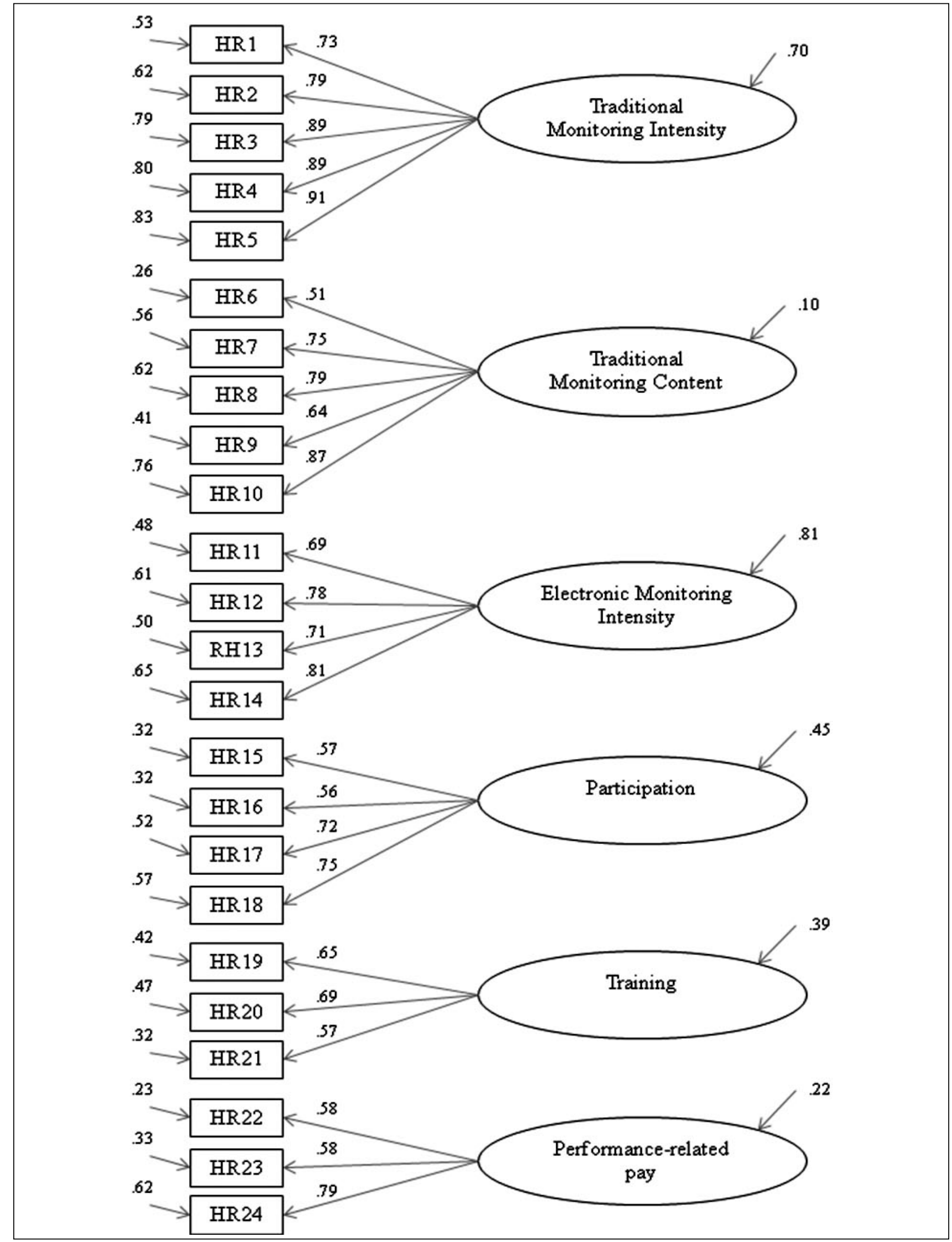


Table 1. Descriptive statistics and correlations of HR practices per call centre

\begin{tabular}{|c|c|c|c|c|c|c|c|c|}
\hline & \multicolumn{3}{|c|}{ Call Centre 1} & \multicolumn{5}{|c|}{ Correlations } \\
\hline & M & SD & $\mathrm{N}$ & 1 & 2 & 3 & 4 & 5 \\
\hline 1. TradMonitInten & 3.61 & .90 & 215 & & & & & \\
\hline 2. TradMonitCont & 4.57 & .53 & & $.34 * * *$ & & & & \\
\hline 3. ElectrMonitInten & 3.55 & .93 & & $.48 * * *$ & $.19 * *$ & & & \\
\hline 4. Participation & 2.79 & .86 & & -.08 & $.23 * *$ & $-.17 *$ & & \\
\hline 5. Training & 4.04 & .77 & & .08 & $.26 * * *$ & -.02 & $.51 * * *$ & \\
\hline \multirow[t]{3}{*}{ 6. PerformRelatedPay } & 3.70 & .79 & & .03 & $.24 * * *$ & .04 & $.30 * * *$ & $.29 * * *$ \\
\hline & \multicolumn{3}{|c|}{ Call Centre 2} & \multicolumn{5}{|c|}{ Correlations } \\
\hline & M & SD & $\mathrm{N}$ & 1 & 2 & 3 & 4 & 5 \\
\hline 1. TradMonitInten & 4.31 & .65 & 45 & & & & & \\
\hline 2. TradMonitCont & 4.57 & .69 & & $.41 * *$ & & & & \\
\hline 3. ElectrMonitInten & 3.66 & .80 & & $.41 * *$ & .12 & & & \\
\hline 4. Participation & 2.79 & .99 & & $.31 *$ & $.36 *$ & $.30 *$ & & \\
\hline 5. Training & 4.45 & .60 & & .27 & $.41 * *$ & .10 & $.35^{*}$ & \\
\hline 6. PerformRelatedPay & 2.42 & .84 & & & .22 & .13 & .20 & .11 \\
\hline
\end{tabular}

\begin{tabular}{|c|c|c|c|c|c|c|c|c|}
\hline & \multicolumn{3}{|c|}{ Call Centre 3} & \multicolumn{5}{|c|}{ Correlations } \\
\hline & $\mathrm{M}$ & SD & $\mathrm{N}$ & 1 & 2 & 3 & 4 & 5 \\
\hline 1. TradMonitInten & 3.99 & .93 & 29 & & & & & \\
\hline 2. TradMonitCont & 4.54 & .60 & & $.52 * *$ & & & & \\
\hline 3. ElectrMonitInten & 3.12 & 1.10 & & $.44 *$ & .15 & & & \\
\hline 4. Participation & 2.84 & .81 & & .30 & .15 & $.48^{* *}$ & & \\
\hline 5. Training & 3.90 & .89 & & .28 & $.40 *$ & .29 & .20 & \\
\hline 6. PerformRelatedPay & 2.30 & .96 & & $.46^{*}$ & $.93 *$ & .29 & .24 & $.42 *$ \\
\hline
\end{tabular}

\begin{tabular}{|c|c|c|c|c|c|c|c|c|}
\hline & \multicolumn{3}{|c|}{ Call Centre 4} & \multicolumn{5}{|c|}{ Correlations } \\
\hline & $\mathrm{M}$ & SD & $\mathrm{N}$ & 1 & 2 & 3 & 4 & 5 \\
\hline 1. TradMonitInten & 4.16 & .83 & 22 & & & & & \\
\hline 2. TradMonitCont & 4.68 & .35 & & $.44^{*}$ & & & & \\
\hline 3. ElectrMonitInten & 2.81 & .96 & & -.07 & .18 & & & \\
\hline 4. Participation & 3.08 & .76 & & .18 & .18 & .02 & & \\
\hline 5. Training & 4.38 & .35 & & $.58 *$ & .28 & .01 & -.02 & \\
\hline 6. PerformRelatedPay & 3.11 & .84 & & .11 & .10 & -.15 & -.02 & .22 \\
\hline
\end{tabular}

\begin{tabular}{|c|c|c|c|c|c|c|c|c|}
\hline & \multicolumn{3}{|c|}{ Call Centre 5} & \multicolumn{5}{|c|}{ Correlations } \\
\hline & M & SD & $\mathrm{N}$ & 1 & 2 & 3 & 4 & 5 \\
\hline 1. TradMonitInten & 4.28 & .71 & 41 & & & & & \\
\hline 2. TradMonitCont & 4.65 & .42 & & $.36 *$ & & & & \\
\hline 3. ElectrMonitInten & 4.01 & .95 & & $.32 *$ & .22 & & & \\
\hline 4. Participation & 2.92 & .68 & & .08 & .06 & .11 & & \\
\hline 5. Training & 4.40 & .65 & & .03 & $.37 *$ & .27 & $.36^{*}$ & \\
\hline \multirow[t]{3}{*}{ 6. PerformRelatedPay } & 4.10 & .89 & & .20 & .21 & .10 & .23 & .29 \\
\hline & \multicolumn{3}{|c|}{ Call Centre 6} & \multicolumn{5}{|c|}{ Correlations } \\
\hline & M & $\mathrm{SD}$ & $\mathrm{N}$ & 1 & 2 & 3 & 4 & 5 \\
\hline 1. TradMonitInten & 4.32 & .69 & 59 & & & & & \\
\hline 2. TradMonitCont & 4.73 & .38 & & $.31 *$ & & & & \\
\hline 3. ElectrMonitInten & 3.88 & 1.01 & & $.41 * *$ & .16 & & & \\
\hline 4. Participation & 2.86 & .90 & & .03 & -.13 & -.08 & & \\
\hline 5. Training & 4.27 & .63 & & $.27 *$ & .19 & .15 & .20 & \\
\hline 6. PerformRelatedPay & 4.14 & .69 & & $.42 *$ & .23 & $.29 *$ & .11 & $.42 * *$ \\
\hline
\end{tabular}


Table 1. Descriptive statistics and correlations of HR practices per call centre (continued)

\begin{tabular}{|c|c|c|c|c|c|c|c|c|}
\hline & \multicolumn{3}{|c|}{ Call Centre 7} & \multicolumn{5}{|c|}{ Correlations } \\
\hline & M & SD & $\mathrm{N}$ & 1 & 2 & 3 & 4 & 5 \\
\hline 1. TradMonitInten & 3.62 & 1.03 & 53 & & & & & \\
\hline 2. TradMonitCont & 4.39 & .71 & & $.61 * * *$ & & & & \\
\hline 3. ElectrMonitInten & 3.61 & 1.11 & & $.50 * * *$ & $.49 * * *$ & & & \\
\hline 4. Participation & 3.34 & .85 & & -.07 & -.12 & -.27 & & \\
\hline 5. Training & 3.81 & .72 & & .13 & .13 & -.17 & $.48 * * *$ & \\
\hline \multirow[t]{3}{*}{ 6. PerformRelatedPay } & 4.09 & .78 & & .16 & .07 & -.12 & .03 & $.28 *$ \\
\hline & \multicolumn{3}{|c|}{ Call Centre 8} & \multicolumn{5}{|c|}{ Correlations } \\
\hline & M & SD & $\mathrm{N}$ & 1 & 2 & 3 & 4 & 5 \\
\hline 1. TradMonitInten & 3.90 & 1.11 & 225 & & & & & \\
\hline 2. TradMonitCont & 4.45 & .76 & & $.70 * * *$ & & & & \\
\hline 3. ElectrMonitInten & 3.53 & 1.19 & & $.59 * * *$ & $.46 * * *$ & & & \\
\hline 4. Participation & 2.57 & .76 & & -.03 & -.09 & -.12 & & \\
\hline 5. Training & 4.13 & .72 & & $31 * * *$ & $.27 * *$ & $.21 * *$ & $.22 * *$ & \\
\hline \multirow[t]{3}{*}{ 6. PerformRelatedPay } & 3.44 & .84 & & .06 & -.03 & -.02 & $.50 * * *$ & $.28 * * *$ \\
\hline & \multicolumn{3}{|c|}{ Call Centre 9} & \multicolumn{5}{|c|}{ Correlations } \\
\hline & M & SD & $\mathrm{N}$ & 1 & 2 & 3 & 4 & 5 \\
\hline 1. TradMonitInten & 4.13 & .90 & 55 & & & & & \\
\hline 2. TradMonitCont & 4.60 & .50 & & $.48 * * *$ & & & & \\
\hline 3. ElectrMonitInten & 4.21 & .85 & & $.54 * * *$ & .15 & & & \\
\hline 4. Participation & 2.60 & .87 & & $.28 *$ & .26 & -.18 & & \\
\hline 5. Training & 4.09 & .81 & & $.39 * *$ & $.27 *$ & .06 & $.49 * * *$ & \\
\hline \multirow[t]{3}{*}{ 6. PerformRelatedPay } & 3.71 & .84 & & $.28^{*}$ & $.41 * *$ & -.02 & $.58 * * *$ & $.54 * * *$ \\
\hline & \multicolumn{3}{|c|}{ Call Centre 10} & \multicolumn{5}{|c|}{ Correlations } \\
\hline & $\mathrm{M}$ & SD & $\mathrm{N}$ & 1 & 2 & 3 & 4 & 5 \\
\hline 1. TradMonitInten & 4.11 & .91 & 30 & & & & & \\
\hline 2. TradMonitCont & 4.59 & .77 & & $.62 * * *$ & & & & \\
\hline 3. ElectrMonitInten & 3.11 & 1.20 & & $.50 * *$ & .29 & & & \\
\hline 4. Participation & 3.30 & .83 & & .03 & .00 & -.13 & & \\
\hline 5. Training & 3.97 & .97 & & .06 & -.18 & .11 & .23 & \\
\hline \multirow[t]{3}{*}{ 6. PerformRelatedPay } & 4.23 & .65 & & .03 & .00 & .00 & .19 & -.14 \\
\hline & \multicolumn{3}{|c|}{ Call Centre 11} & \multicolumn{5}{|c|}{ Correlations } \\
\hline & M & SD & $\mathrm{N}$ & 1 & 2 & 3 & 4 & 5 \\
\hline 1. TradMonitInten & 3.86 & 1.26 & 37 & & & & & \\
\hline 2. TradMonitCont & 4.13 & .77 & & $.84 * * *$ & & & & \\
\hline 3. ElectrMonitInten & 3.96 & 1.28 & & $.88 * * *$ & $.75 * * *$ & & & \\
\hline 4. Participation & 3.56 & .86 & & .17 & .11 & .14 & & \\
\hline 5. Training & 3.80 & .73 & & .31 & .24 & $.38 *$ & $.46 * *$ & \\
\hline 6. PerformRelatedPay & 2.28 & .60 & & -.28 & -.15 & -.25 & .29 & .32 \\
\hline
\end{tabular}

Note. TradMonitInten $=$ Traditional monitoring intensity; TradMonitCont $=$ Traditional monitoring content; ElectrMonitInten = Electronic monitoring intensity; $* * *$. Correlation is significant at the .001 level; **. Correlation is significant at the .01 level; * Correlation is significant at the .05 level.

sented low internal consistency. Nevertheless, taking into account its importance to HR systems in call centres we have decided to keep them (Wood et al., 2006; Holman, 2005).

Table 1 shows the means, standard deviations, correlations and sample sizes for employee data sets at all call centers studied.

\section{Criterion-related validity}

In order to analyse criterion-related validity, HR managers were interviewed and a case-study approach was adopted in this stage. Based on interviews' content analysis, the 11 call centres that participated in our study were described and characterized in terms of the 
presence/intensity of HR practices. Due to the diversity in call centres configurations (Frenkel et al., 1998; Kinnie et al., 2000), we aimed at gathering detailed information about their HR practices and the inter-relations among them. The content analysis of the HR interviews' resumes followed two steps: The first step involved the physical relocation of phrases and expressions, subdividing the data into relevant segments. In this first step, researchers used the structure provided by the guidelines of the interviews. In these guidelines, each HR practice had been previously defined and operationalized. However, due to the semi-structured nature of the interviews, some segments of information naturally emerged aggregated in one single block of information and were therefore considered together and others, because poor information was generated, were eventually eliminated from the analysis. The second phase involved finding interpretive criteria for organizing information (encoding) and looking for patterns in blocks of information and between them, so conclusions could be drawn. The process of content analysis was individually performed by two researchers, who independently analyzed the data. Researchers had previous experience conducting qualitative analysis in organizational behaviour research, and received common training for conducting these analyses. Subsequently, the divisions and encodings performed by each researcher were compared and a final coding was reached. In areas where the two did not agree, definitions were clarified and, most of the times, consensus was reached. This process of interjudges can increase the accuracy and reliability of qualitative data analysis (Breakwell, 2000). Inter-ratter agreement was $87 \%$, which is indicator of agreement, thereby data reliability (Breakwell, 2000).

Results demonstrate that all call centres have implemented both HR control and involvement practices, thereby demonstrating that the content validity of the test was relevant to evaluate HR practices in call centres. Each dimension will be followed by a small description of its implementation in call centres.

Electronic performance monitoring. The findings reveal that all call centres have highly structured electronic monitoring systems. Performance monitoring is daily registered through an informatics system that automatically records performance data. All centres give feedback to their employees either on a weekly or on a monthly basis. As expected, the difference among call centres was found not in terms of whether or not they relied on electronic monitoring, but in its combined use with calls length control. We found that some call centres implemented HR electronic monitoring only for calls' management flows and statistics (call centres 2, 3, 4,7 , and 10), while others formally controlled and evaluated length of calls $(1,5,6,8,9$, and 11).

Here, it is part of performance evaluation that, in $90 \%$ of calls, call's length doesn't overcome 220 and 360 seconds, respectively. We have display screens on the wall, and each employee has a permanent digital control, on PC screen, that keeps him informed of time (call centre 9)

Our teams are aware of the importance of controlling time length. Each employee has a computer divisor that permanently controls time length and counts down remaining seconds. In this call centre, maximum length is 50 seconds (call centre 5).

Our workers don't have explicit time limits of calls. Nevertheless, their performance evaluation is dependent on the accomplishment of quantitative criteria, such as a minimum number of calls answered per hour (call centre 8).

Employees can't overcome 180 seconds per call, otherwise they will be penalized in their performance evaluation. Calls' length is tightly monitored and employees have on-line screens that regulate all call centre's flow of calls. There is a permanent divisor on workers' PC screen that counts down time duration (call centre 6).

Traditional performance monitoring. Also in what concerns traditional monitoring, all call centres have developed monitoring systems that allow them to monitor the quality of communication. All call centres emphasised communication quality as an important strategic goal, but only few have reported the usage of dialogue scripting $(2,4,8,9,11)$ and its adherence being monitored and evaluated.

Here, supervisors have to listen to employees' calls every 30 minutes. They have a check list and they must ensure employees keep up with the guidelines (call centre 4).

Supervisors are responsible for qualitative monitoring of calls. They listen to calls, and check for script adherence (...) also, the client, itself, listens to calls and monitors employee performance. In addition, The Quality department records and listens to 2 calls/day/worker (call centre 9).

The client has an active role in workers' qualitative performance monitoring. On a daily basis, the client records, listens and evaluates calls. (...) There is a script that employees must follow and the client has a strict guideline to check on (call centre 8).

Training. The findings reveal that, with no exceptions, selection and initial training are inter-related, with initial training being composed of tests and training practices that are taken into consideration in the selection process. In what concerns ongoing training, all call centres recognize it as important for improving performance and recycle knowledge. Training needs are mainly identified through performance monitoring practices.

In this call centre, operators are recruited and selected directly by R\&S and Training department. The selection process begins with a telephone interview, which has as main objectives to evaluate the diction, the capacities of communication and attitude. This is the only stage of the process that is individual. From 
this moment, the candidates enter a 5-day training in group, which is organized as follows: Day 1: Presentation of the company and the general conditions; Day 2: Training in Quality (general knowledge and simulations). The remaining training days are eliminatory; Day 3: The operators are allocated to a specific campaign, and start having specific training; Day 4: Techniques of sale (upgraded to the campaign); Day 5: Training practice: Simulations (in class or in call center). Beyond this initial training, operators may also have training that is provided for the supervision, individually, in the form of coaching, or recycling in group, in the classroom (call centre 2).

When an operator is selected for this call center, he/she is integrated in a training program that can last from 9 to 12 weeks, depending on covering only technical knowledge or also including the sales component. This training has a theoretical and a practical component, individuals must respond to written tests, which are the basis for evaluation and are eliminatory. The initial training is promoted by the group of Training and Quality. All the training that a subsequent operator may have results from the qualitative assessments made quarterly by the Training and Quality (call centre 1).

Performance related pay. In call centres $2,3,4$, and 11 monthly income is not variable. There are no other incentives or bonus depending on performance. All other call centres present different "wage packages" depending on performance evaluations. In call centres $1,5,6,7,8,9$, and 10 wages are composed of a fixed and a variable part and in call centre 7, freelancers' income is totally dependent of performance evaluation.

There is one prize money quarterly calculated from the assessments of the quantitative and qualitative criteria. Good results in the monthly evaluation of quantitative performance allow access to monetary premium, while the result obtained in quarterly quality assessment may determine the award, if the assessment is good or reduction or cancellation of it if the assessment is low (call centre 1).

In the Project 9, there is also one monthly prize money formally introduced to the best team and weekly prizes for the best players of each team (call centre 9).

Participation Programs. It is the supervisor who, on a daily basis, implements small games/challenges and bonus to promote team cohesion, problems' discussion and resolution. In most call centres, there are meetings to discuss problems and difficulties and operators participate in some call centres projects. Outside call centres' facilities, many activities are implemented, such as football games and social activities and workers' participation is high. Employees are also expected to mention specific training needs and sometimes more experienced employees meet and try to solve some unexpected situations and propose possible solutions (Call centres 2, 3, 4, 5, 6, 7, 10).

We have weekly meetings of the supervisors with their operators, the bi-annual meetings between each operator and the manager of the call centre, where they discuss issues important to the operator and their concerns about career, claims and suggestions (call centre 7).

The evaluations of individual performance are based a conversation between the operator and his supervisor, where they debate workers' strengths and aspects for improvement and training activities to develop. In this evaluation process, the operator is an active participant. We also have a quiz with questions about the business. Operators and supervisors also created the "Wall of Questions", where employees can anonymously write the issues/questions they want to see answered, and subsequently, supervisor will post their answers. We also have the election of the employee of the month (call centre 10).

As we can see (Table 1), all call centres adopt some performance monitoring practices. Nevertheless, a closer look on the performance requirements shows that only in some call centres these monitoring practices are designed to check for adherence on dialogue script and length call's regulation and that these characteristics allow a distinction to be made between call centres. It is our assumption that when monitoring practices are combined with surveillance of script adherence or with time length regulation, they are categorized as more intensive monitoring practices. In terms of HR involvement practices, one can conclude that all call centres demonstrate a high concern for training programs. Nevertheless, we can identify some differences in call centres in terms of participation programs and performance related pay that allow us to distinguish call centres.

Finally, in order to evaluate scales' scores convergent validity, it was important to analyse whether employees' perceptions of each HR practice varied in accordance to the call centres' description in terms of that specific practice being measured. Based on the differences found on the presence/intensity of each HR practice, call centres were coded 0 indicating the absence or low intensity/frequency and 1 indicating the presence or high intensity/frequency in each HR practice (Table 2).

Employees were coded according to their call centres' category in each of these HR practices. For example, in terms of intensity of electronic monitoring, it was created a new categorical variable in which workers employed in call centres 2, 3, 4, 7, and 10 were coded 0 , indicating lower intensity of electronic monitoring, whereas employees from call centres 1,5,6,8,9 and 11 were coded 1 indicating higher intensity of this HR practice (See Table 1). However, when according to interviews, HR practices were similar among call centres (content clarity of traditional monitoring and training programs), all individuals remained coded with their call centres identification in order to confirm that there were no significant differences in their perceptions of these practices. 
Table 2. HR practices in call centres based on HR managers' interviews

\begin{tabular}{|c|c|c|c|c|c|c|}
\hline $\begin{array}{l}\text { Call } \\
\text { Centres }\end{array}$ & $\begin{array}{c}\text { Intensity of } \\
\text { Performance } \\
\text { Electronic } \\
\text { Monitoring }\end{array}$ & $\begin{array}{c}\text { Intensity of } \\
\text { Performance } \\
\text { Traditional } \\
\text { Monitoring }\end{array}$ & $\begin{array}{c}\text { Content of } \\
\text { Performance } \\
\text { Traditional } \\
\text { Monitoring }\end{array}$ & Training & $\begin{array}{l}\text { Performance } \\
\text { Related Pay }\end{array}$ & $\begin{array}{c}\text { Participation } \\
\text { Programs }\end{array}$ \\
\hline 1 & 1 & 0 & 1 & 1 & 1 & 0 \\
\hline 2 & 0 & 1 & 1 & 1 & 0 & 1 \\
\hline 3 & 0 & 0 & 1 & 1 & 0 & 1 \\
\hline 4 & 0 & 1 & 1 & 1 & 0 & 1 \\
\hline 5 & 1 & 0 & 1 & 1 & 1 & 1 \\
\hline 6 & 1 & 0 & 1 & 1 & 1 & 1 \\
\hline 7 (a) & 0 & 0 & 1 & 1 & 1 & 1 \\
\hline 8 & 1 & 1 & 1 & 1 & 1 & 0 \\
\hline 9 & 1 & 1 & 1 & 1 & 1 & 0 \\
\hline 10 & 0 & 0 & 1 & 1 & 1 & 1 \\
\hline 11 & 1 & 1 & 1 & 1 & 0 & 0 \\
\hline
\end{tabular}

Note. (a)- Only considered Free Lancers (85\%); 0 = Lower Intensity; absence; 1= Higher Intensity; presence.

In order to analyse if the variance of employees' perceptions of each HR practice could be explained by call centres characterization, several chi-square analysis were conducted. As expected, results show a significant main effect of call centres characterization on perceived intensity of both electronic and traditional monitoring as well as on employees' perception of participation programs and performance related pay. In what concerns the perceived intensity of electronic performance monitoring, results show that call centres characterization are a significant source of variance $(\mathrm{F}$ $\left.(1,809)=12.08 ; r<.01 ; \eta^{2}=.02\right)$, showing that those workers employed in call centres that had already been identified as having implement more intense electronic performance monitoring also perceive a higher intensity of this practice $(\mathrm{M}=3.69)$ when compared to the employees from the other call centres $(\mathrm{M}=3.37)$. In addition, results also demonstrate a significant effect on the intensity of traditional monitoring performance $\left(\mathrm{F}(1,810)=5.21 ; r<.05 ; \eta^{2}=.01\right)$. In this case, employees belonging to call centres that had been previously identified as having implemented more intense traditional monitoring practices perceive higher intensity of this practice $(M=3.99)$, when compared to the employees from the other call centres $(\mathrm{M}=$ 3.83). In what concerns participation programs there is also evidence of a significant effect of previous characterization $\left(\mathrm{F}(1,809)=20.27 ; r<.001 ; \eta^{2}=.02\right)$. Employees in call centres previously identified as having implemented more participation programs report higher levels of this practice $(\mathrm{M}=3.01)$ than employees in other call centres $(M=2.73)$. Finally, employees from call centres that were characterized as having more performance related pay, also reported higher levels of this practice $(M=3.73)$ when compared to employees in other call centres $(\mathrm{M}=2.47 ; \mathrm{F}(1,810)=$ $\left.247.90 ; r<.001 ; \eta^{2}=.24\right)$. In what concerns training programs and the content of traditional monitoring practices, based on previous data analysis from inter- views, we did not expected differences among call centres. However, contrary to the expected, results from chi-square analysis demonstrates that there is a significant main effect of call centre on training $(F(10,799)$ $\left.=4.26 ; r<.001 ; \eta^{2}=.05\right)$ and the content of traditional monitoring practices $\left(\mathrm{F}(10,799)=3.25 ; r<.001 ; \eta^{2}\right.$ $=.04)$. These results indicate that there are significant differences in employees' perceptions of these two HR practices that allow call centres to be differentiated, despite that data collected through interviews didn't allow its differentiation.

\section{Discussion}

Using a sample of Portuguese call centres, the current study was set out to develop a questionnaire to evaluate HR practices in call centres and validate its scores. Despite being considered an important variable in understanding call centre employees' attitudes, behaviors, stress and well being (Batt \& Colvin, 2011; Holman, 2005), research on HR practices in call centers is usually based on qualitative information or on checklists that evaluate the presence/absence of HR practices (Holman et al., 2002). In this research, a 24item questionnaire was developed and call centres' employees were asked to answer the HR practices questionnaire. Construct validity was assessed by an exploratory factorial analysis that confirmed the sixfactor structure and reliability was assessed by alpha coefficient index, as an indicator of the scale scores' internal consistency. Most of the scale scores presented good psychometric properties. In order to assess criterion-related validity, the same HR practices were assessed in interviews with the HR managers. By analysing whether employees' perceptions matched call centres characteristics and whether workers employed in call centres with different characteristics, also differed in their evaluations of HR practices, 
allowed us to evaluate concurrent convergent validity. This combination of qualitative and quantitative data of the same construct, on the one hand, and having considered two different sources of information (HR managers and employees), on the other hand, has increased the validity of assessments of HR practices. Specifically, we have chosen an accurate and credible source for the interview to characterize the criterion data, and both qualitative and quantitative information were collected at the same time but with different methodologies (Messick, 1980). Results demonstrated that employees' perceptions varied in accordance to what had been described by HR managers. Workers employed in call centres that were characterized as having implemented more intensive electronic and traditional monitoring practices, when asked about these practices, also reported higher levels of perceived intensity. In the same vein, individuals who perceive more participation programs or more performance related-pay, are employed in call centres that were described as having higher levels of these practices. This research demonstrated that employees' perceptions of HR practices vary in accordance to the call centres' categorization, thereby gathering evidence for the convergent validity of the questionnaires' scale scores. We believe this study adds to the existent literature of HRM in call centres by developing an instrument specifically conceived for this working context. As previously described, most research relies on check-lists or in qualitative information regarding HR practices (Boselie et al., 2005). More importantly, this instrument provides a balanced characterization of HR systems in call centres, including both HR control and HR involvement practices. We believe this instrument can help researchers develop a more comprehensive understanding of HR systems in call centres and directly reply to some authors' call to take account of different possible configurations of HR practices when studying this specific sector (Kinnie et al., 2000; Holman, 2005).

However, we must acknowledge that scale construction was not entirely successful because two scale scores presented low internal reliability values (training and performance related pay) and, particularly the training scale allowed an unexpected distinction to be made between call centres. Therefore, future studies should try to gather more detailed information about training programs' content and its purposes, both in terms of call centres' characterization as in terms of employees' perceptions. Furthermore, a new sample of items regarding these two HR scales should be designed and included in the questionnaire, for future depuration. Future studies should also continue to study the possible differences in the perceptions of HR practices between managers and employees. Several authors have demonstrated that there might be a real discrepancy in the way HR practices are designed and implemented and how they are experienced by employees (Guest, 2001; Nishii et al., 2008; Bashshur et al., 2011). A recent study by Bashshur et al. (2011) has demonstrated that the perceptual agreement among managers and their teams can be crucial and have an impact on individuals and teams' well-being. In this study, in what concerns the content of traditional monitoring practices, analysis of variance detected an unexpected difference between employees' perceptions among different call centres. As this scale's score presented good internal reliability, we believe that it was the information gathered from the interviews that proved to be insufficient to characterize how well employees were informed of the parameters taken in consideration during performance monitoring. In line with other studies, we must also consider the possibility of a disagreement between HR managers' perception and employees' perception regarding the content of traditional monitoring practices. Nishii et al. (2008) have demonstrated that employees make varying attributions for the same HR practices, and that these attributions are differentially associated with employees' outcomes. Indeed, we must acknowledge that variance in responses can be due to error variance, such as measurement errors that we're analysing in this study, or be due to true variance, reflecting real differences between managers and employees' perceptions. As this study was designed, we're not able to disentangle true and error variance. Future studies should keep this limitation in mind when studying HR systems.

Some empirical conclusions can be drawn from this study. First, the present study contributed to the development of an instrument to assess an important area of calls centres management: HR practices. We believe this is a valuable contribute to the studies in this sector, and that the questionnaire developed here presents some promising results that should be studied and improved in further investigations. Second, the emerged picture from interviews and questionnaires is similar to those reported in other studies (Holman \& Wood, 2002). Even though this similarity is promising, it is important to develop studies in call centres from other countries in order to analyse the stability of scales' psychometric properties and its possible generalization to other cultural contexts. In this study, we have developed a 24-item questionnaire that measures performance-monitoring practices, training, participation and performance related pay practices in 11 Portuguese call centres. Third, future investigation should try to study more call centres and increase configurations' diversity. Even though we were able to demonstrate significant differences between employees' perception of HR practices across call centres, we must acknowledge that the significant main effect of characterization over employees' perception of HR practices is a weak effect, as eta squared values show. We must recognise that we established high levels of within-groups variance in call centres' HR characterization. This characterization relied on self-reported 
data, which is usually embedded in workers' emotional reactions to the context, and, again, we must take into account our inability to distinguish between real from random error variance (Nishii et al., 2008). Also, we must acknowledge that little is known about how HR systems were implemented in call centers and their results communicated to workers (Bashshur et al., 2011). Further investigation should continue to develop studies to improve the HR practices questionnaire and overcome these limitations.

\section{References}

Arbuckle, J. L. (2003). AMOS 5.0 user's guide. Chicago: Small Waters Corporation.

Ball, K. (2010). Workplace surveillance: an overview. Labor History, 51, 87-106.

Batt, R. (2002). Managing customer services: human resources practices, quit rates and sales growth. Academy of Management Journal, 45, 587-597.

Batt, R. (1999). Work design, technology and performance in costumer service and sales. Industrial and Labor Relations Review, 52, 539-564.

Batt, R. \& Appelbaum, E. (1995). Worker participation in diverse settings: does the form affect the outcome, and if so, who benefits? British Journal of Industrial Relations, 33, 353-378.

Batt, R. \& Colvin, A. J. S. (2011). An employment systems approach to turnover: Human resources practices, quits, dismissals, and performance. Academy of Management Journal, 54, 695-717.

Bashshur, M. R., Hernández, A., \& González-Roma, V. (2011). When managers and their teams disagree: A longitudinal look at the consequences of differences in perceptions of organizational support. Journal of Applied Psychology, 96, 558-573.

Boselie, P., Dietz, G., \& Boon, C. (2005). Commonalities and contradictions in HRM and performance research Human Resource Management Journal, 15, 67-94.

Breakwell, G. M., (2000). Interviewing. In C. Fife-Schaw (Ed.). Research Methods inPsychology. Sage, London.

Chambel, M. J. \& Castanheira, F. (2010). Trabalhar num call center: Dos mitos à realidade [Work in a call center: From myths to reality]. Lisboa: RH Editora.

Combs, J., Liu, Y., Hall, A. M., \& Ketchen, D. (2006). How much do high-performance work practices matters? A meta-analysis of their effects on organizational performance. Personnel Psychology, 59, 501-528.

Cotton, J. L. (1993). Employee involvement. Methods for improving performance and work attitudes. London: Sage.

DBK (2007). Estudio sectores de portugal: Call Centers [Study on Portuguese Sectors: Call Centres]. Madrid

Deery, S., Iverson, R., \& Walsh, J. (2002). Work relationships in telephone call centers: Understanding emotional exhaustion and employee withdrawal. Journal of Management Studies, 39, 471-496.
Frenkel, S. J., Tam, M., Korczynski, M., \& Shire, K. (1998). Beyond bureaucracy? Work organization in call centres. The International Journal of Human Resource Management, 9, 954-979.

Guest, D. (2001). Human resource management: When research confronts theory. The International Journal of Human Resource Management, 12, 1092-1106.

Holman, D. (2005). Call Centres. In D. Holman, T. D. Wall, C. Clegg, P. Sparrow and A. Howard (Eds.) The essentials of the new workplace: A guide to the human impact of modern work practices. (111-131). John Wiley \& Sons, Ltd.

Holman, D., Chissick, C., \& Totterdell, P. (2002). The effects of performance monitoring on emotional labour and well being in call centres. Motivation and Emotion, 26, 57-81.

Holman, D., Frenkel, S., Sorensen, O., \& Wood, S. (2009). Work design variation and outcomes in call centers: Strategic choice and institutional explanations. Industrial and Labor Relations Review, 62, 510-532.

Holman, D. \& Wood, S. (2002) Human resource management in call centres. Institute of Work Psychology, Memo $\mathrm{n}^{\circ} 260$, University of Sheffield.

Hu, L. \& Bentler, P. M. (1999). Cutoff criteria for fit indexes in covariance structure analysis: Conventional criteria versus new alternatives. Structural Equation Modeling, 6, $1-55$.

Kinnie, N., Hutchinson, S. \& Purcell, J. (2000). Fun and surveillance: The paradox of high commitment management in call centres. International Journal of Human Resource Management, 11, 967-985.

Kline, P. (1994). The Handbook of Psychological Testing. New York: Routledge.

Lepak, D. P., Liao, H., Chung, Y., \& Harden, E.E. (2006). A conceptual review of human resource systems in strategic human resource management research. Research in Personnel and Human Resources Management, 25, 217271.

Messick, S. (1980). Test validity and ethics of assessment. American Psychologist, 35, 1012-1027.

Nishii, L. H., Lepak, D. P., \& Schneider, B. (2008). Employee attributions of the "why" of HR practices: Their effects on employee attitudes and behaviors, and customer satisfaction. Personnel Psychology, 61, 503-545

Podsakoff, P. M., MacKenzie, S. B., Lee, J.-Y., \& Podsakoff, N. P. (2003). Common method biases in behavioral research: A critical review of the literature and recommended remedies. Journal of Applied Psychology, 88, 879-903.

Russell, D. W. (2002). In search of the underlying dimensions: The use (and abuse) of factor analysis in Personality and Social Psychology Bulletin. Personality and Social Psychology Bulletin, 28, 1629-1646.

Russell, B. (2008) Call centers: A decade of research. International Journal of Management Reviews 10, 195219.

Schneider, B. \& Bowen, D. E. (1993). The service organization: Human resources management is crucial. Group Dynamics, 21, 39-52. 
Sprigg, C. A. \& Jackson, P.R. (2006). Call centers as lean service environments: Job-related strain and the mediating role of work design. Journal of Occupational Health Psychology, 11, 197-212.

Taylor, O. \& Bain, P. (1999). «An assembly line in the head»: Work and employee relations in the call centre. Industrial Relations Journal, 30, 101-117.
Taylor, P., Hyman, J., Mulvey, G., \& Bain, P., (2002). Work organization, control and the experience of work in call centres. Work, Employment and Society, 16, 133150.

Wood, S., Holman, D., \& Stride, C. (2006). Human resource management and performance in UK call centres. British Journal of Industrial Relations, 44, 99-122.

Manuscript Received: 05/12/2011 Revision Received: 01/03/2012

Accepted: 05/03/2012 